\title{
Análise do crescimento tumoral e sua relação com as alterações na síndrome da anorexia-caquexia em ratos senis.
}

\author{
Rafaela Rossi Rosolen (IC), Laís Rosa Viana (PG) e Maria Cristina Cintra Gomes-Marcondes (PQ)
}

\section{Resumo}

O desenvolvimento de neoplasia maligna promove no organismo alterações bioquímicas e metabólicas que culminam no grave estado de degradação denominado caquexia. Utilizamos ferramentas inovadoras como ressonância magnética para analisar os efeitos do câncer-caquexia em animais senis, portadores do carcinoma de Walker 256, modelo experimental desta síndrome. Essas análises podem proporcionar novas diretrizes para o tratamento do câncer e novos conhecimentos da evolução do estado caquético.

Palavras chave: Caquexia- câncer, Tumor Walker 256, metabolômica.

\section{Introdução}

O crescimento do câncer promove no organismo alterações bioquímicas e metabólicas que culminam no grave estado denominado caquexia. Caracterizado pela intensa perda involuntária de peso em função da intensa depleção da proteína muscular, o estado caquético resulta na redução da qualidade e expectativa de vida dos pacientes portadores de câncer. O objetivo desse trabalho foi analisar a evolução tumoral e a mobilização dos substratos metabólicos em portadores de neoplasia maligna durante a senilidade em ratos Wistar senis. 35 animais foram distribuídos em sete diferentes grupos, a saber: controle adulto (CA); controle senil (CS); portadores do tumor

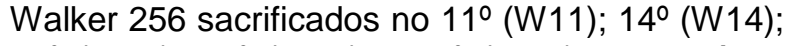

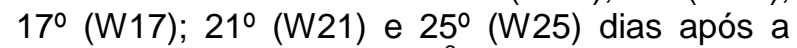
inoculação única de $2 \times 10^{6}$ células neoplásicas viáveis no subcutâneo do flanco direito. Após o sacrifício dos animais portadores do carcinoma de Walker 256 e dos animais controles, retirou-se sangue através de punção cardíaca e, após a centrifugação do mesmo, o soro obtido foi submetido ao processo de filtração para a realização de análise metabolômica através de espectroscopia por ressonância magnética nuclear (RMN) com o objetivo de avaliar as vias/metabólitos que possam estar envolvidos no processo de estabelecimento da caquexia-câncer.

\section{Resultados e Discussão}

Verificou-se sempre proporcional a evolução do tumor, redução acentuada do peso corporal; aumento crescente da concentração de alantonina, 2-hidroxibutirato, acetona e nmetilhistidina (indicador de degradação de proteína), dentre outros, associado a redução acentuada da glicose e glutamina sérica.

\section{Curva de ganho de peso}
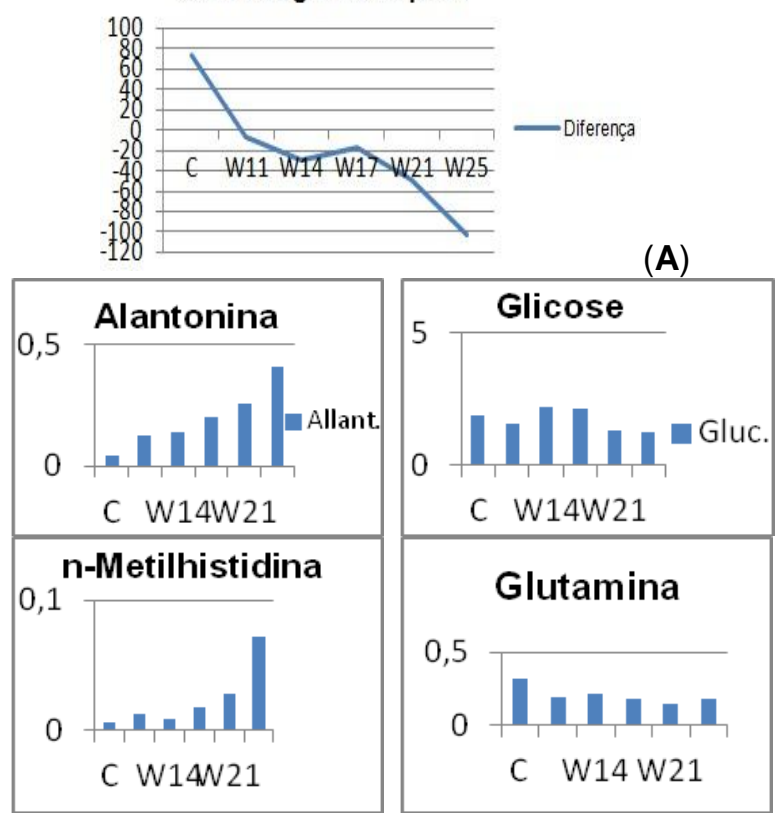

Figura 1 - Curva de ganho de peso (g) ao longo das diferentes datas de sacrifício em função da evolução do crescimento tumoral (A) e perfil de variação de alguns dos metabólitos analisados por RMN.

\section{Conclusões}

Esses resultados mostram que a evolução tumoral necessita de substratos energéticos e estruturais para seu crescimento (glicose e glutamina) e promove intensa espoliação do hospedeiro, como degradação de proteína e intensa perda de massa muscular (redução do peso relativo do musculo gastrocnêmio), promovendo severa perda de peso, culminando no estado caquético do animal.

\section{Agradecimentos}

Fapesp 2013/16115-1; 2010/00209-9. CNPq 302863/2013-3; CNPq-PIBIC/UNICAMP 